\title{
AVALIAÇÃO DA PRODUÇÃO DE BIOGÁS A PARTIR DE RESÍDUOS DE UMA INDÚSTRIA DE CELULOSE
}

\author{
${ }^{1}$ Alexandre vieira Sylvio \\ ${ }^{2}$ Ramon Souza Ferreira
}

\section{RESUMO}

O biogás é um composto gerado durante o processo em que bactérias anaeróbicas degradam materiais orgânicos. Este trabalho teve como objetivo avaliar a produção de biogás utilizando os resíduos sólidos gerados na indústria de papel Celulose Nipo-Brasileira, localizada no município de Belo Oriente, estado de Minas Gerais. Foram implantados dez tratamentos com diferentes concentrações de resíduos coletado na indústria: lodo biológico (LB), proveniente do tratamento de esgoto gerado na indústria, o dregs (D) e a munha de carvão (MC), provenientes do processo de beneficiamento da celulose. As composições utilizadas nos tratamentos utilizando LB/D/MC foram: $90 \% / 5 \% / 5 \%$; $80 \% / 10 \% / 10 \% ; 70 \% / 15 \% / 15 \% ; 60 \% / 20 \% / 20 \% ; 50 \% / 25 \% / 25 \% ; 50 \% / 40 \% / 10 \% ; 50 \% / 10 \% / 40 \% ; 70 \% / 30 \% / 0 \%$; $70 \% / 0 \% / 30 \% ; 100 \% / 0 \% / 0 \%$ na relação peso. Os materiais foram misturados totalizando $0,1 \mathrm{~kg}$ para cada recipiente e condicionados em frascos de vidro (reatores) de $500 \mathrm{ml}$ com adição de $100 \mathrm{ml}$ de água, lacrados hermeticamente e mantidos no laboratório de química da água/UFVJM. O biogás gerado foi avaliado utilizando um manômetro digital com leituras semanais durante doze semanas. O tratamento que apresentou melhor resultado na produção total de biogás foi a mistura de $80 \%$ de lodo biológico, $10 \%$ de dregs e $10 \%$ de munha de carvão. Dos dez tratamentos, quatro não produziram biogás. Nestes tratamentos, o teor de munha na mistura estava acima de $20 \%$, indicando que quantidades elevadas deste elemento na mistura inibem a atividade microbiológica e a produção de biogás. Todos os demais tratamentos produziram quantidades significativas de biogás.

Palavras-chave: Bactérias anaeróbicas. Biodigestão. Metano. Resíduos.

\section{EVALUATION OF BIOGAS PRODUCTION FROM WASTE FROM A CELLULOSE INDUSTRY}

\begin{abstract}
Biogas is a compound generated during the process in which anaerobic bacteria degrade organic materials. This study aimed to evaluate the production of biogas using solid waste generated in the Celulose Nipo-Brasileira paper industry located in the municipality of Belo Oriente, state of Minas Gerais. Ten treatments were implemented with different concentrations of waste collected in the industry: biological sludge (LB) from the treatment of sewage generated in the industry, the dregs (D) and the coal slug (MC) from the pulp processing process. The treatments LB/D/MC used were: $90 \% / 5 \% / 5 \% ; 80 \% / 10 \% / 10 \% ; 70 \% / 15 \% / 15 \% ; 60 \% / 20 \% / 20 \% ; 50 \% / 25 \% / 25 \% ; 50 \% / 40 \% / 10 \% ; \quad 50 \% / 10 \% / 40 \%$; $70 \% / 30 \% / 0 \% ; 70 \% / 0 \% / 30 \% ; 100 \% / 0 \% / 0 \%$ in volume ratio. The materials were mixed in different proportions, totaling $0.1 \mathrm{~kg}$ for each container and conditioned in glass containers (reactors) of $500 \mathrm{ml}$ with the addition of water, hermetically sealed and kept in the soil and water chemistry laboratory at UFVJM. Biogas production was evaluated using a digital manometer with weekly readings for a period of 12 weeks. The treatment that showed the best result in the total production of biogas was a mixture of $80 \%$ biological sludge, $10 \%$ dregs and $10 \%$ coal sludge. Of the ten treatments performed, four did not produce biogas. In these treatments, the charcoal wal content in the mixture was above $20 \%$, indicating that amounts of this element above the proportion of $20 \%$ in the mixture inhibit microbiological activity and biogas production. All other treatments produced significant amounts of biogas.
\end{abstract}

Key words: Anaerobic bacteria. Biodigestion. Methane. Waste.

\footnotetext{
${ }^{1}$ Universidade Federal dos Vales do Jequitinhonha e Mucuri - UFVJM, Minas Gerais, (Brasil). https://orcid.org/00000001-7251-7816 E-mail: asylvio@ hotmail.com

${ }^{2}$ Universidade Federal dos Vales do Jequitinhonha e Mucuri - UFVJM, Minas Gerais, (Brasil). https://orcid.org/00000002-1629-1741 E-mail: marromsf@hotmail.com
} 


\section{INTRODUÇÃO}

Produzir de forma sustentável tem sido um grande desafio para empresas que cumprem as leis ambientais. Diversos processos industriais ainda geram grandes impactos negativos ao ambiente, porém atualmente, em decorrência da preocupação com o meio ambiente, uma nova visão do governo e da sociedade tem surgido para que os resíduos sejam transformados em fonte de novas matérias-primas (Silva, 2016).

No processo mundial de industrialização da década de 70 , indústrias de celulose e papel também evoluíram em busca de novas tecnologias e sistemas que melhorassem seu desempenho. Durante este período, a criação de novas estruturas e novas tecnologias de produção também culminaram em novos problemas como aumento das emissões atmosféricas e geração de resíduos, muitos deles perigosos. Dessa forma, novos problemas ambientais surgiram atingindo grandes proporções com a poluição da água, ar e solo (Bueno, 2018).

Em 2016, a produção brasileira de celulose teve um aumento significativo em relação ao ano de 2015 , tendo sido produzidas 18,8 milhões de toneladas, incluindo o processo de fabricação para fibra curta (eucalipto) e longa (pinus). A quantidade exportada foi de 12,9 milhões de toneladas com um aumento de 11,9\% em relação ao ano de 2015 (Ibá, 2017). Com esses números, o Brasil subiu no ranking mundial de produção ficando atrás apenas dos Estados Unidos.

As indústrias de celulose e papel trabalham com políticas ambientais sempre visando a utilização consciente dos recursos naturais e a redução da geração de resíduos. No ano de 2016, foram geradas no segmento 47,8 milhões de toneladas de resíduos sólidos, sendo 70,5\% (33,7 milhões de toneladas) no setor florestal e 29,5\% no setor industrial (Ibá, 2017). Segundo a empresa Cenibra - Celulose Nipo-Brasileira (2018), para cada tonelada de celulose produzida são gerados 208 quilos de resíduos.

Atualmente, a forma mais utilizada para o tratamento de alguns resíduos não perigosos e orgânicos provenientes da indústria de celulose e papel é a decomposição biológica. Essa técnica exige grandes áreas para estocagem dos resíduos e longos períodos para que ocorra a decomposição completa de todo o material (Pinheiro, 2008). Alguns deles, por ser tratar de resíduos com alta relação $\mathrm{C} / \mathrm{N}$, inicialmente exigem uma decomposição prévia do material que pode ser realizada com a inoculação de agentes decompositores. Porém, essa técnica exige investimentos maiores e frequente monitoramento.

A geração do biogás ocorre na biodigestão de materiais orgânicos em sistemas fechados onde uma porção da biomassa é transformada pela ação de bactérias metanogênicas na ausência de oxigênio. No processo de fermentação e geração do biogás, o principal composto produzido de interesse para geração de energia é o gás metano. O biodigestor é constituído por um local de entrada da biomassa ou efluente líquido, o local onde ocorrerá a biodigestão, o armazenamento do biogás e o local de saída da matéria orgânica estabilizada (Lustosa e Medeiros, 2014).

Para Cheunbarn e Pagilla (2000), vários fatores podem influenciar e afetar o processo de biodigestão promovido pelas bactérias, sendo a temperatura um dos mais importantes. Em relação ao $\mathrm{pH}$ ideal para o processo de biodigestão, Foresti (1998) descreve que o intervalo deve estar entre 6,8 e 7,5 podendo ser ampliado para valores entre 6,0 e 8,0. De acordo com Moura (2012), nos meios de acidez elevada as atividades enzimáticas bacterianas de importância para o processo são anuladas. Por esse motivo, o $\mathrm{pH}$ ideal para esse tipo de processo é o mais próximo a neutralidade.

$\mathrm{Na}$ relação Carbono/Nitrogênio (C/N) do sistema, de acordo com Sgorlon et. al. (2011), a proporção deve ser a ideal para a atividade bacteriana, transformando os compostos orgânicos para que o desempenho do processo seja elevado. De acordo com Reichert (2005), os valores ideais para a relação $\mathrm{C} / \mathrm{N}$ estão situados entre 20 e 30.

A composição química dos resíduos orgânicos utilizados é importante na avaliação do processo de produção do biogás, considerando tanto os fatores que estimulam a atividade microbiológica durante a biodigestão quanto as que inibem as reações, fundamentais na determinação tanto da qualidade quanto da quantidade de biogás gerado. Galbiatti et al. (2010) 
testaram misturas de materiais orgânicos na produção de biogás envolvendo esterco de ave de corte com cama de capim Napier, esterco suíno, bovino e bagaço de cana de açúcar. Os autores verificaram que a utilização do esterco bovino como substrato promoveu maior concentração de gás metano no biogás e a mistura do bagaço de cana com esterco bovino tendeu a reduzir a produção de biogás.

Konzen (1983) afirma que o substrato oriundo de dejetos suínos possui elevado potencial energético para a produção de biogás, considerando que $70 \%$ dos sólidos totais presentes são compostos por sólidos voláteis, elementos essenciais no processo de biodigestão anaeróbica. Com a utilização de resíduos orgânicos compostos por restos de frutas e vegetais como substrato na produção de biogás, Gomes et al. (2006) obtiveram rendimentos de até 0,8 litros de biogás por quilo de sólidos voláteis. Deivanai e Kasturi Bai (1995), utilizando resíduos da bananeira como substrato, alcançaram rendimento máximo de 9,221 litros por quilo de sólidos totais.

Suzuki et al (2012), avaliando a produção de biogás utilizando cama de frango como substrato, verificaram que a produção inicial foi lenta, mas constante e em crescimento ao longo dos dias de avaliação. Segundo os autores, as características heterogêneas da cama de frango apresentando predominantemente materiais de lenta degradação como madeira rica em celulose e lignina reduzem a taxa de produção de biogás.

Outros estudos realizados com resíduos de frutas, restos de alimentos domiciliares e esterco bovino geraram biogás nas concentrações de 53,7\%, 63,8\% e 41\%, respectivamente (Zhang et al., 2013).

Segundo Lannicelli (2008), o biogás com características satisfatórias em relação ao aproveitamento energético deve apresentar entre 50 e $75 \%$ de metano. Considerando estes valores, Silva et al. (2020) verificaram que a geração de metano utilizando resíduos sólidos urbanos domésticos da região de Maceió em Alagoas atingiu média de $60 \%$ de concentração de gás metano no biogás, apresentando potencial energético satisfatório.

Vários estudos foram desenvolvidos considerando a geração de biogás utilizando resíduos industriais de larga escala.

Souza et al. (2009) avaliaram o potencial de produção de biogás, utilizando resíduos da indústria cervejeira, o bagaço de malte. Com a utilização de $2,3 \mathrm{~kg}$ de material por reator obtiveram entre 6,614 e 6,763 litros de biogás demonstrando o excelente potencial desta matéria-prima.

Santos et al (2018) avaliaram a produção de biogás utilizando resíduos de uma fábrica de produção de suco de laranja. Utilizou-se o resíduo de bagaço da laranja associado ao lodo industrial gerado em reatores de batelada com capacidade para $250 \mathrm{ml}$. Verificaram que o potencial de geração energética dos resíduos de laranja, tendo o lodo como agente inoculante acelerando a produção de biogás, atingiu valores de concentração de metano acima de $54 \%$.

Silva et al (2020) avaliaram a produção de biogás utilizando como biomassa o lodo de esgoto e restos de poda de árvores. Verificaram que a mistura de maior potencial de produção de biomassa foi na proporção de 3:1 (lodo de esgoto:biomassa de poda).

O presente trabalho teve como objetivo avaliar o potencial de produção de biogás e gás metano utilizando resíduos orgânicos produzidos por uma fábrica de celulose da região Leste de Minas Gerais e o seu potencial de geração de energia elétrica.

\section{METODOLOGIA}

O estudo foi conduzido no laboratório de solos da Universidade Federal dos Vales do Jequitinhonha e Mucuri, Campus Teófilo Otoni, Minas Gerais. Neste trabalho foram coletados alguns dos resíduos gerados pela indústria de papel e celulose Celulose Nipo-Brasileira (Cenibra, 2018), localizada no município de Belo Oriente em Minas Gerais. Os resíduos coletados foram o lodo biológico, munha de carvão e dregs, na área de descarte dos resíduos no interior da fábrica.

O lodo biológico é proveniente dos tratamentos de água e esgoto da indústria. É gerado em sistemas biológicos aeróbios utilizando lodos ativados e lagoas aeradas. A munha de carvão é a 
sobra orgânica da queima do carvão, originária da limpeza dos fornos onde foram realizadas a queima de resíduos de madeira. O dregs apresenta coloração escura, sendo originado da queima incompleta do licor negro na caldeira de recuperação, seguido de precipitação que ocorre em meio alcalino (Rodrigues et al., 2016)

Os materiais foram condicionados em sacos plásticos e lacrados para transporte. Para determinação do teor de umidade, foi coletada uma amostra de cada material e pesados em balança de precisão para determinação do peso úmido. Em seguida, os materiais foram colocados em estufa a $65^{\circ} \mathrm{C}$ por 72 horas até a obtenção do peso seco e posterior cálculo da porcentagem de umidade por meio da diferença entre o peso inicial e o final das amostras. Outra parte das amostras dos materiais coletados foram conduzidas ao laboratório de química do Departamento de Meio Ambiente e Qualidade da Cenibra para caracterização química.

Após a preparação dos materiais foi realizada a montagem experimental. Os materiais foram secados a sombra e destorroados. Após o destorroamento, os materiais foram peneirados em peneira de malha 5,0 mm. As partículas maiores que 5,0 $\mathrm{mm}$ diâmetro foram descartadas. Os tratamentos consistiram de diferentes misturas dos materiais nas seguintes proporções de Lodo biológico (LB); dregs (D); munha de carvão (MC) (Tabela 1).

Neste ensaio, foram utilizados dez tratamentos. Cada tratamento foi definido com proporções diferentes dos materiais residuais totalizando $0,1 \mathrm{~kg}$ em cada reator.

Tabela 1 - Proporção de elementos na mistura (peso)

\begin{tabular}{llccc}
\hline Tratamentos & Lodo biológico & Dregs & $\begin{array}{c}\text { Munha de } \\
\text { carvão }\end{array}$ & Total \\
\hline $1^{\circ}$ tratamento & $90 \%(0,090 \mathrm{~kg})$ & $5 \%(0,005 \mathrm{~kg})$ & $5 \%(0,005 \mathrm{~kg})$ & $100 \%$ \\
\hline $2^{\circ}$ tratamento & $80 \%(0,080 \mathrm{~kg})$ & $10 \%(0,010 \mathrm{~kg})$ & $10 \%(0,010 \mathrm{~kg})$ & $100 \%$ \\
\hline $3^{\circ}$ tratamento & $70 \%(0,070 \mathrm{~kg})$ & $15 \%(0,015 \mathrm{~kg})$ & $15 \%(0,015 \mathrm{~kg})$ & $100 \%$ \\
\hline $4^{\circ}$ tratamento & $60 \%(0,060 \mathrm{~kg})$ & $20 \%(0,020 \mathrm{~kg})$ & $20 \%(0,020 \mathrm{~kg})$ & $100 \%$ \\
\hline $5^{\circ}$ tratamento & $50 \%(0,050 \mathrm{~kg})$ & $25 \%(0,025 \mathrm{~kg})$ & $25 \%(0,025 \mathrm{~kg})$ & $100 \%$ \\
\hline $6^{\circ}$ tratamento & $50 \%(0,050 \mathrm{~kg})$ & $40 \%(0,040 \mathrm{~kg})$ & $10 \%(0,010 \mathrm{~kg})$ & $100 \%$ \\
\hline $7^{\circ}$ tratamento & $50 \%(0,050 \mathrm{~kg})$ & $10 \%(0,010 \mathrm{~kg})$ & $40 \%(0,040 \mathrm{~kg})$ & $100 \%$ \\
\hline $8^{\circ}$ tratamento & $70 \%(0,070 \mathrm{~kg})$ & $30 \%(0,030 \mathrm{~kg})$ & $0 \%(0,000 \mathrm{~kg})$ & $100 \%$ \\
\hline $9^{\circ}$ tratamento & $70 \%(0,070 \mathrm{~kg})$ & $0 \%(0,000 \mathrm{~kg})$ & $30 \%(0,030 \mathrm{~kg})$ & $100 \%$ \\
\hline $10^{\circ}$ tratamento & $100 \%(0,100 \mathrm{~kg})$ & $0 \%(0,000 \mathrm{~kg})$ & $0 \%(0,000 \mathrm{~kg})$ & $100 \%$ \\
\hline
\end{tabular}

Fonte: Autor

Os materiais foram preparados na proporção de peso (Tabela 1). Foram construídos reatores biológicos de vidro comum com capacidade para 500mL com sistema de lacre utilizando rolhas de silicone visando evitar a entrada de oxigênio externo e criar um ambiente anaeróbico. Após a preparação das misturas dos resíduos e disposição no interior dos reatores foi adicionado $100 \mathrm{~mL}$ de água destilada. Os materiais foram misturados e, em seguida promovido o fechamento do reator. Os reatores foram mantidos em temperatura de, aproximadamente, $30^{\circ} \mathrm{C}$.

Os gases gerados e armazenados no interior dos reatores foram quantificados utilizando um manômetro manual com agulha inserido na câmara de armazenamento dos gases através da rolha de silicone. A leitura da pressão dos gases gerados na câmara de armazenamento foi realizada semanalmente durante o período de 12 semanas. Foi utilizado para a leitura o manômetro Novotest DPG219, série DPG 0/1.000 PSI acoplado a uma mangueira rígida e na outra extremidade a uma agulha com a função de interligar o gás do reator ao manômetro. A unidade de medida utilizada nas leituras foi em pound force per square inch (PSI) e, posteriormente, transformada em KPa seguindo a conversão e o Sistema Internacional de Unidades. Adotou-se os valores de $1 \mathrm{psi}=6,895 \times 10^{3} \mathrm{~Pa}$ (pascal) e $1 \mathrm{~Pa}=145,04 \times 10^{-6}$ psi. A fórmula de cálculo utilizada para se obter o quantitativo de gás pela pressão foi a Equação 1 dos gases perfeitos. 


$$
\begin{aligned}
& \frac{P 1 V 1}{T 1}=\frac{P 2 . V 2}{T 2} \quad \text { (Equação 1) } \\
& \text { Onde: } \\
& \mathrm{P}=\text { pressão (pascal) } \\
& \left.\mathrm{V}=\text { volume (m }{ }^{3}\right) \\
& \mathrm{T}=\text { temperatura (kelvin). }
\end{aligned}
$$

Com a obtenção da leitura da pressão e a média das temperaturas diárias registradas durante o experimento, foi calculado o quantitativo de biogás gerado.

$\mathrm{O}$ experimento foi conduzido em triplicata e o delineamento experimental utilizado foi o inteiramente casualisado, com todas as parcelas experimentais dispostas ao acaso. Foram aplicados os testes de Anova para avaliar a produção potencial anual estimada de biogás e metano e a determinação de significância pelo teste $\mathrm{F}$. Na avaliação das diferenças entre os tratamentos, foi aplicado o teste de Tukey a p<0,05. Para análise da evolução da produção do biogás nos reatores, ao longo das 12 semanas avaliadas, foram utilizados os testes de regressão múltipla.

Com os resultados obtidos nos reatores e o cálculo de estimativa de produção de biogás e gás metano, realizou-se o cálculo da estimativa de produção de biogás em larga escala utilizando a composição média dos resíduos gerados anualmente pela empresa e o seu potencial teórico de geração de energia elétrica.

Com os valores totais de geração de gás metano produzido no processo, avaliou-se o seu potencial de geração de energia elétrica e o valor bruto gerado anualmente, em reais, considerando o valor de comercialização do KWh pelas distribuidoras no estado de Minas Gerais em 2020.

\section{RESULTADOS E DISCUSSÃO}

O lodo proveniente da Cenibra apresentou concentração de matéria orgânica de $86,87 \%$, de cinzas $13,13 \%$ e de sílica $5,83 \%$. Os demais elementos identificados presentes no lodo são apresentados na Figura 1A. Verifica-se que o elemento mineral presente no lodo biológico em maior concentração é o alumínio com valores superiores a $12 \%$. Este elemento é encontrado em abundância na natureza, mas em elevadas concentrações pode se tornar tóxico para plantas e microrganismos, limitando suas atividades fisiológicas e bioquímicas. Vieira (2017) avaliaram a adição de diferentes concentrações de alumínio no lodo gerado em uma estação de tratamento de esgoto no processo de geração de gás metano. As doses aplicadas variaram entre 0,5 e 2,0 g. $\mathrm{L}^{-1}$ de $\mathrm{Al}(\mathrm{OH})_{3}$. Apesar de não verificarem mudanças na remoção de sólidos voláteis, a presença de maiores concentrações de alumínio no lodo reduz o processo de remoção da DQO, atingindo quedas de $80 \%$ na eficiência do processo aos 39 dias. Os autores citam que os teores de alumínio no meio orgânico não podem ser desconsiderados no processo de geração de gás metano em biodigestores anaeróbicos.

Outros trabalhos demonstram que o uso de polímeros orgânicos e agentes coagulantes no processo de tratamento do lodo biológico como o sulfato de alumínio, cloreto férrico e policloreto de alumínio, promovem a inibição da atividade dos microrganismos acetogênicos e metanogênicos no processo de biodigestão (Kim e Chung, 2015; Ju et al., 2016).

Os finos de carvão também denominados munha ou moinha de carvão são constituídos por um pó orgânico composto por alto teor de cinzas. A munha é proveniente do manuseio e beneficiamento da madeira que são carbonizados durante o processo de geração de energia por meio da queima de cascas e outros resíduos gerados no processo de preparação da madeira.

A munha de carvão apresenta composição química diversificada contendo potássio, magnésio, cálcio, dentre outros elementos essenciais (Figura 1B). As reduzidas concentrações de metais pesados na munha de carvão, tais como o chumbo $(\mathrm{Pb})$, o lítio $(\mathrm{Li})$ e o cromo $(\mathrm{Cr})$, demonstram um reduzido grau de contaminação do material e comprometimento da atividade 
microbiológica. Segundo Gianfreda e Bollag (1996), metais pesados ou metais tóxicos, que não apresentam função metabólica essencial, atuam diretamente, interferindo nos processos bioquímicos dos microrganismos reduzindo sua atividade enzimática e, consequentemente, o metabolismo microbiano e suas atividades, incluindo a produção de biogás.

Apesar dos reduzidos valores de metais pesados presentes na munha de carvão, alguns autores reportam que não apenas os níveis de metais pesados presentes no substrato interferem na atividade microbiológica, mas também a natureza do substrato disponível (Obbard e Jones, 1993). As formas em que os metais se encontram e as fontes de contaminação também devem ser considerados (Silva e Vieira, 2008).

O dregs é proveniente do processo de recuperação de reagentes. Sua origem se dá por meio de sais de reposição, tais como o sulfato de sódio, silicatos e aluminatos refratários das caldeiras de recuperação, corrosão dos digestores e material particulado de combustão incompleta (Rodrigues et al, 2016). É um subproduto que apresenta potencial para ser utilizado no setor agropecuário e florestal corrigindo a acidez do solo por suas propriedades alcalinas. Seu pH é elevado, próximo a 10,0, de cor escura proveniente da queima incompleta de licor negro e precipitação. Segundo Ostrem e Themelis (2004), o pH do substrato do biodigestor com características ácidas indica um acúmulo de ácidos orgânicos, fator que compromete a atividade microbiológica e a produção do biogás e a presença do dregs no substrato pode reduzir o problema.

O dregs utilizado neste trabalho possui $14,50 \%$ de sólidos totais e $74,04 \mathrm{~g} . \mathrm{L}^{-1}$ de álcali total. Este resíduo apresenta elevada concentração de $\mathrm{CaO}$ e $\mathrm{MgO}$, características importantes para melhoria do equilíbrio dos substratos orgânicos presentes nos biodigestores, mas também teores consideráveis de $\mathrm{NaO}$ promotor da salinização de ambientes (Figura 1C).

Alguns autores descrevem a ação inibidora de sais inorgânicos nos processos de fermentação microbiológica com o cloreto de sódio $(\mathrm{NaCl})$ interferindo significativamente no metabolismo dos microrganismos (Tajima et al., 1966; Umemoto et al., 1967). Rodrigues e Santanna (2001) verificaram, em meio semissólido, que o acréscimo de $0,6 \mathrm{M}$ de $\mathrm{NaCl}$ no meio de cultura promoveu uma redução no desenvolvimento de biomassa microbiana de S. cerevisiae em 27,62\%. Experimento conduzido por Norkrans (1966) também demonstrou a ação do $\mathrm{NaCl}$ no desenvolvimento do $S$. cerevisiae. Verificou que o acréscimo de $4 \%$ de $\mathrm{NaCl}$ no meio de cultivo microbiológico reduziu o crescimento da levedura entre 10 e $15 \%$ e com a adição de $8 \%$ de sal no meio, a redução da biomassa foi de $90 \%$. O processo de redução da atividade microbiológica e de sua biomassa pela presença do sal é justificado pela perda de água das células microbianas para o meio externo devido a diferença de potencial eletroquímico entre os meios intra e intercelular promovendo o estresse e o comprometimento da integridade da membrana celular, resultando na plasmólise das células microbianas (Christian e Waltho, 1964). Desta forma, a presença de aproximadamente $8 \%$ de $\mathrm{Na}_{2} \mathrm{O}$ no dregs em estudo deve ser avaliado de forma específica. 

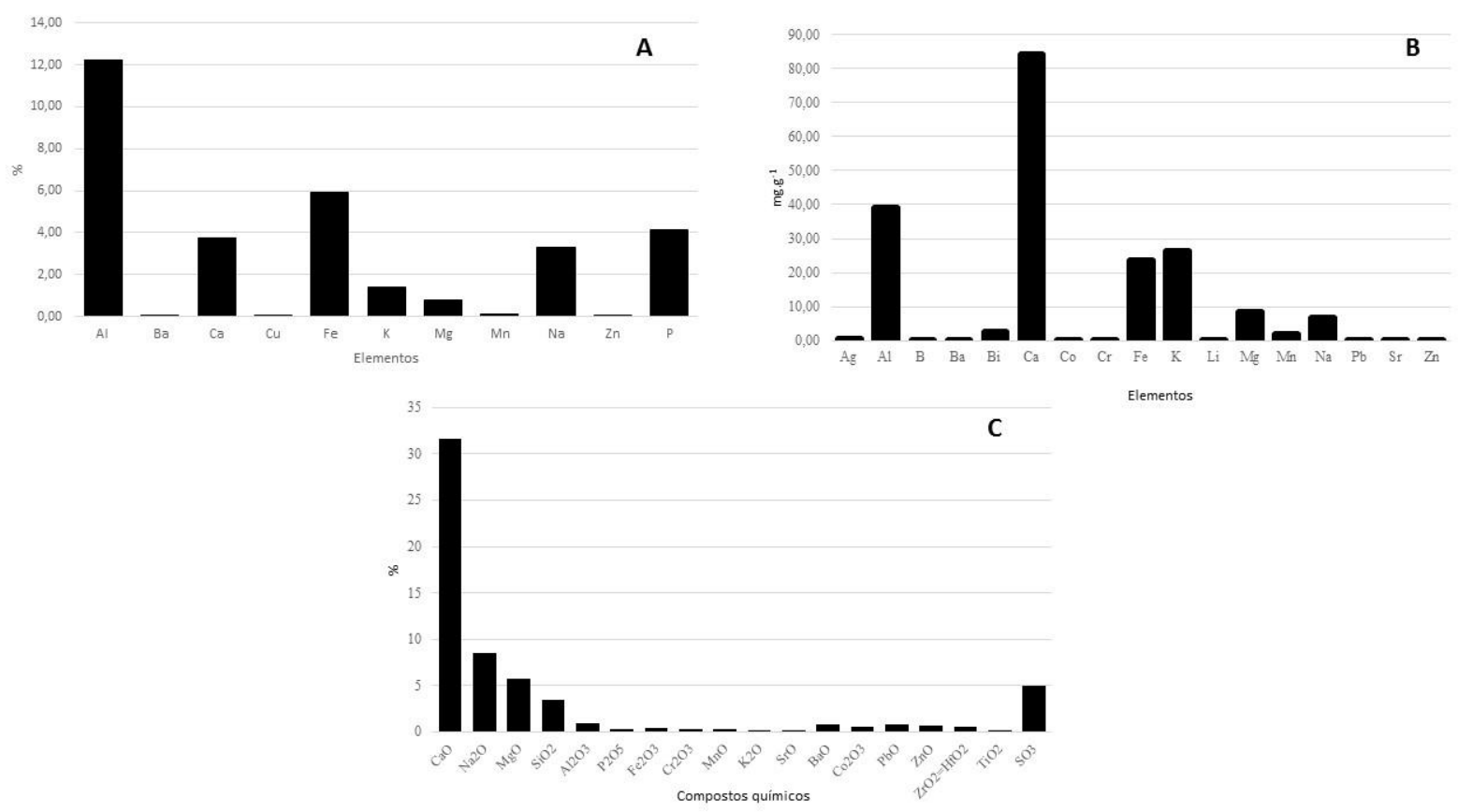

Figura 1. Composição química do lodo biológico (A), munha de carvão (B) e dregs (C) coletado na fábrica de celulose. Fonte - Os autores

Na Figura 2, verifica-se os modelos de regressão ajustados indicando as diferenças de comportamentos de produção de biogás entre os diferentes substratos avaliados.
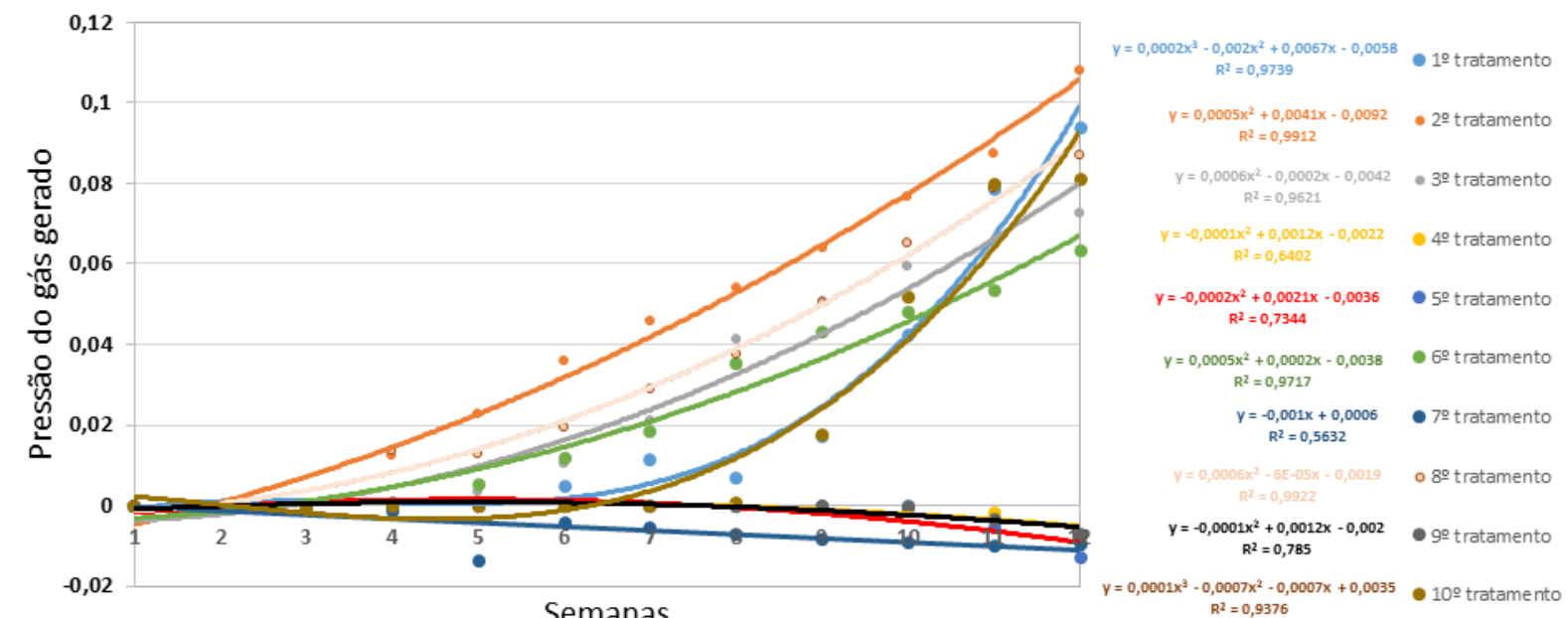

$1^{\circ}$ Trat.: 90\%LB, 5\%D, 5\%MC; $2^{\circ}$ Trat.: $80 \% \mathrm{LB}, 10 \% \mathrm{D}, 10 \% \mathrm{MC} ; 3^{\circ}$ Trat.: $70 \% \mathrm{LB}, 15 \% \mathrm{D}, 15 \% \mathrm{MC}$; 4o Trat.: $60 \% \mathrm{LB}, 20 \% \mathrm{D}$, 20\%MC; 5o Trat.: 50\%LB, 25\%D, 25\%MC; $6^{\circ}$ Trat.: 50\%LB, 40\%D, 10\%MC; $7^{\circ}$ Trat. $50 \%$ LB, $10 \%$ D, $40 \%$ MC; $8^{\circ}$ Trat.: $70 \%$ LB, $30 \% \mathrm{D}, 0 \% \mathrm{MC} ; 9^{\circ}$ Trat.: $70 \% \mathrm{LB}, 0 \% \mathrm{D}, 30 \% \mathrm{MC} ; 10^{\circ}$ Trat.: $100 \% \mathrm{LB}, 0 \% \mathrm{D}, 0 \% \mathrm{MC}$

LB- Lodo Biológico

D-Dregs

MC-Munha dse Carvão.

Figura 2. Modelos ajustados de produção de biogás com a utilização de diferentes proporções de misturas de resíduos da fábrica de celulose Cenibra.

Fonte - Os autores 
Observa-se a taxa de produção dos gases nas diferentes misturas realizadas com os resíduos ao longo de 12 semanas. Da $1^{\mathrm{a}}$ semana até a $3^{\mathrm{a}}$ semana de avaliação, não foi identificado a produção de biogás sem nenhum dos reatores. Provavelmente os microrganismos encontravam-se na fase lag de desenvolvimento. Nesta fase, os microrganismos estão se adaptando ao ambiente e o seu processo celular bioquímico e metabólico se ajustando ao consumo dos materiais orgânicos. A partir da $4^{a}$ semana, a alteração da pressão dos gases (produção) foi constatada em alguns reatores. Os tratamentos que apresentaram maior pico inicial foram o $8^{\circ}$ tratamento $(70 \% \mathrm{LB}$ e $30 \% \mathrm{D})$ e o $2^{\circ}$ tratamento $(80 \% \mathrm{LB}, 10 \% \mathrm{D}$ e $10 \% \mathrm{MC})$ e sem respostas dos demais tratamentos. Até a $12^{\mathrm{a}}$ semana os dois tratamentos apresentaram evolução constante na produção de biogás com o $2^{\circ}$ tratamento apresentando maior valor na produção final de biogás, comparado com os demais tratamentos. $\mathrm{O} 8^{\circ}$ tratamento apresentou um início promissor na produção de biogás ao término da avaliação na $12^{\mathrm{a}}$ semana ocupando o $3^{\circ}$ lugar geral entre todos os tratamentos.

Entre a $4^{\mathrm{a}}$ e a $6^{\mathrm{a}}$ semanas, outros três tratamentos iniciaram a produção de biogás: o $1^{\mathrm{o}}$ tratamento $(90 \% \mathrm{LB}, 5 \% \mathrm{D}$ e $5 \% \mathrm{MC})$, o $3^{\circ}$ tratamento $(70 \% \mathrm{LB}, 15 \% \mathrm{D}$ e $15 \% \mathrm{MC})$ e $6^{\circ}$ tratamento $(50 \% \mathrm{LB}, 40 \% \mathrm{D}$ e $10 \% \mathrm{MC})$. Os $3^{\circ}$ e $6^{\circ}$ tratamentos apresentaram um desempenho semelhante no acúmulo e na produção de biogás ao longo das semanas avaliadas com a medição final na última semana (12 $\mathrm{a}$ semana) com valores próximos do $3^{\mathrm{o}}$ tratamento, ficando na $5^{\mathrm{a}}$ posição geral na produção de biogás ao final do processo avaliativo e o $6^{\circ}$ tratamento na sexta posição ao final da $12^{\mathrm{a}}$ semana.

$\mathrm{O} 1^{\circ}$ tratamento apresentou um desenvolvimento na produção de biogás bastante tímido até a $8^{\text {a }}$ semana. A partir deste período foi intensificada a produção de biogás, atingindo o $2^{\circ}$ lugar na produção final, na última semana de avaliação. O tratamento que também apresentou produção final de biogás foi o $10^{\circ}$ tratamento $\left(100 \%\right.$ LB), processo que teve início apenas a partir da $8^{\mathrm{a}}$ semana de avaliação e apresentando uma elevada taxa de produção de biogás até a $12^{\mathrm{a}}$.

$\mathrm{O} 4^{\circ}$ tratamento $(60 \% \mathrm{LB}, 20 \% \mathrm{D}$ e $20 \% \mathrm{MC})$, o $5^{\circ}$ tratamento $(50 \% \mathrm{LB}, 25 \% \mathrm{D}$ e $25 \% \mathrm{MC}) \mathrm{e}$ o $9^{\circ}$ tratamento $(70 \% \mathrm{LB}, 0 \% \mathrm{D}$ e $30 \% \mathrm{MC})$ não registraram qualquer tipo de produção de biogás até a $9^{\mathrm{a}}$ semana de avaliação. Da $10^{\mathrm{a}}$ a $12^{\mathrm{a}}$ semana, os valores de pressão do biogás foram negativos indicando o consumo dos gases iniciais presentes no reator, provavelmente o oxigênio sem a reposição de outros gases que deveria ter sido realizado pelos microrganismos anaeróbicos e facultativos.

De todos os tratamentos testados, o menos promissor foi o $7^{\circ}$ tratamento $(50 \% \mathrm{LB}, 10 \% \mathrm{D}$ e $40 \% \mathrm{MC})$. Neste tratamento, entre a $4^{\mathrm{a}}$ e a $5^{\mathrm{a}}$ semanas de avaliação, os valores de pressão nos reatores tornaram-se negativos, permanecendo desta forma até a $12^{\mathrm{a}}$ semana avaliada.

As diferentes respostas dos tratamentos a produção de biogás podem estar associadas principalmente a relação carbono/nitrogênio $(\mathrm{C} / \mathrm{N})$ dos diferentes materiais. Budziak et al. (2004) caracterizaram o lodo de esgoto biológico de uma indústria de celulose com 47,57\% de carbono total e $4,15 \%$ de nitrogênio total; uma relação $\mathrm{C} / \mathrm{N}$ de 11,46 , valores abaixo da faixa considerada ideal entre 20 e 30, segundo Ostrem e Themelis (2004). Estes mesmos autores citam que uma relação $\mathrm{C} / \mathrm{N}$ muito reduzida pode indicar um substrato com elevada concentração de nitrogênio. Neste caso, durante o início das atividades de decomposição do substrato promovido pelos microrganismos aeróbicos o mesmo será balanceado com a transformação e a liberação gasosa do excesso de nitrogênio na forma de amônia. $\mathrm{O}$ acúmulo deste elemento em ambiente fechado, nos biorreatores, pode promover, dentre outros problemas, a elevação do $\mathrm{pH}$ do meio e inibição do desenvolvimento de grande parte das bactérias que atuam no processo de produção do biogás. Carvalho (2002) encontrou valores diferentes, principalmente em relação ao nitrogênio onde identificou no mesmo tipo de material $0,8 \%$ de nitrogênio total e teor de carbono total de 45,56\% perfazendo uma relação $\mathrm{C} / \mathrm{N}$ próximo de 57 , valor elevado que pode reduzir a atividade microbiológica. Barreto (2008) caracterizou o lodo ativado de uma indústria de celulose do estado de São Paulo com apenas 17,96\% de carbono, 0,68\% de nitrogênio e uma relação C/N de 26,4, mais adequada a atividade microbiológica os reatores. Estes resultados indicam uma grande diversidade de características químicas dos lodos biológicos gerados nas estações de tratamento das fábricas de 
celulose, indicando que o seu manejo para a produção de biogás é dependente de uma prévia análise química dos materiais.

Os demais compostos residuais da empresa de celulose utilizados neste trabalho, apesar de em menores proporções nas misturas dos substratos avaliados, interferiram significativamente no processo, principalmente na relação C/N. Carvalho (2002), por exemplo, analisando o dregs de uma indústria de celulose, identificou um teor de carbono de $8,89 \%$ e de nitrogênio de $0,08 \%$, acarretando em uma relação $\mathrm{C} / \mathrm{N}$ de 111,13 ; valores que comprometem a atividade bioquímica no reator. Arroja e Louro (2005) encontraram valores ainda menores para o nitrogênio no dregs coletado em uma indústria de celulose em Portugal. Os valores indicaram 0,003\% de nitrogênio total no material, quase inexistente.

Apesar deste aspecto negativo, Carvalho (2002) e Almeida et al. (2007) identificaram pH do dregs entre 10 e 11, podendo este elemento atuar como moderador de $\mathrm{pH}$ do substrato do reator. Já na munha de carvão, praticamente foi encontrado nitrogênio devido a sua volatilização durante o processo de queima. Mendonça (2017) identificou apenas 0,005\% de nitrogênio total em moinha de carvão coletada em alto forno.

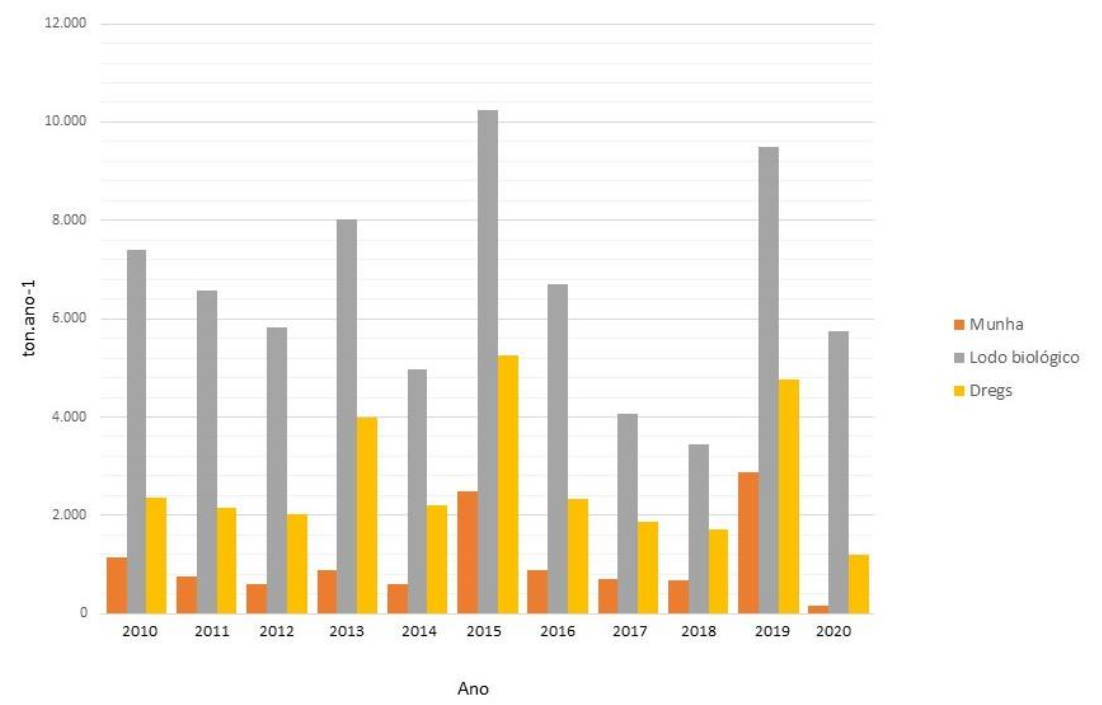

Figura 3. Quantidade de munha de carvão, lodo biológico e dregs gerados pela Cenibra entre os anos de 2010 e 2020.

Fonte - Os autores

Tabela 2 - Média, desvio-padrão e coeficiente de variação dos resíduos avaliados gerados pela Cenibra entre os anos de 2010 e 2020.

\begin{tabular}{cccc}
\hline & Munha de Carvão & Lodo Biológico & Dregs \\
\hline Média (ton.ano ${ }^{-1}$ ) & 1.069 & 6.588 & 2.711 \\
\hline Desvio-padrão & 835,28 & 2115,48 & 1326,05 \\
\hline $\begin{array}{c}\text { Coeficiente de } \\
\text { Variação }(\%)\end{array}$ & 78,11 & 32,10 & 48,91 \\
\hline
\end{tabular}

Fonte: Os autores

Observa-se, na Figura 3, a flutuação de produção dos diferentes resíduos pela empresa Cenibra entre os anos de 2010 e 2020 e utilizados neste trabalho. Em todos os anos avaliados, o lodo biológico foi o resíduo registrado em maior quantidade, atingindo mais de 10.000 toneladas 
geradas em 2015. A sua menor quantidade foi registrada em 2018 com valores próximos a 3.500 toneladas, redução de, aproximadamente, $65 \%$ em relação a 2015. O dregs foi o segundo resíduo de maior registro com quantidades oscilando entre 1.000 e 5.000 toneladas por ano. A munha de carvão foi o resíduo utilizado neste experimento e com menor quantidade de registro, oscilando entre pouco mais de 400 toneladas até 2.500 toneladas por ano, gerado pela fábrica. Verifica-se que o pico de produção de todos os resíduos ocorreu nos anos de 2015 e 2019. De modo geral, neste período avaliado, a média de registro de geração de munha de carvão por ano foi de 1.069 toneladas; de lodo biológico foi de 6.588 toneladas e dregs de 2.711 toneladas, com maior oscilação de registro entre os anos avaliados da munha de carvão com coeficiente de variação de $78,11 \%$ (Tabela 2). Segundo Paiva (2007) e Rodrigues (2004), apesar de contribuir de forma positiva na economia, a indústria de papel e celulose gera milhares de toneladas de resíduos em suas operações, tornando-se um inconveniente para as fábricas em relação ao seu destino, sendo o setor frequentemente associado a problemas de âmbito ambiental.

Estes resultados na oscilação anual de resíduos podem ser explicados pela grande variação internacional na comercialização de celulose, processos que altera a intensidade de produção da indústria e por consequência, a geração de resíduos. Outra explicação pode estar associada a utilização destes resíduos, principalmente nas plantações de eucalipto, como fertilizantes orgânicos. As oscilações de produção decorrentes do mercado global foram registradas por Toresan (2012), que descreveu um vigoroso incremento na demanda mundial de celulose no período compreendido entre 2000 e 2008, caracterizado pelo aumento das exportações. E em 2009, em razão da crise global, um recuo significativo na comercialização aos níveis de 2005.

Tabela 3 - Quantidade de biogás e metano gerados na última avaliação (12ª semana) nos ensaios e a sua estimativa de produção, considerando a média anual de geração destes resíduos pela empresa de celulose.

\begin{tabular}{crrrr}
\hline Tratamento & Biogás $\left(\mathbf{m}^{3}\right)^{\mathbf{1}}$ & Metano $\left(\mathbf{m}^{3}\right)^{\mathbf{2}}$ & Biogás $\left(\mathbf{m}^{3} \cdot \mathbf{a n o}^{-1}\right)^{\mathbf{3}}$ & Metano $\left(\mathbf{m}^{3} \cdot \mathbf{a n o} \mathbf{0}^{-1}\right)^{\mathbf{4}}$ \\
\hline $1^{\circ}$ tratamento & 0,1171 & 0,0644 & $1.390 .887 \mathrm{~b}$ & $764.988 \mathrm{ab}$ \\
\hline $2^{\circ}$ tratamento & 0,1350 & 0,0743 & $1.803 .937 \mathrm{a}$ & $992.165 \mathrm{a}$ \\
\hline $3^{\circ}$ tratamento & 0,0908 & 0,0499 & $1.386 .645 \mathrm{~b}$ & $762.655 \mathrm{ab}$ \\
\hline $4^{\circ}$ tratamento & $-0,0103$ & 0 & $0 \mathrm{~d}$ & $0 \mathrm{c}$ \\
\hline $5^{\circ}$ tratamento & $-0,0164$ & 0 & $0 \mathrm{~d}$ & $0 \mathrm{c}$ \\
\hline $6^{\circ}$ tratamento & 0,0793 & 0,0436 & $1.695 .434 \mathrm{ab}$ & $932.488 \mathrm{a}$ \\
\hline $7^{\circ}$ tratamento & $-0,0122$ & 0 & $0 \mathrm{~d}$ & $0 \mathrm{c}$ \\
\hline $8^{\circ}$ tratamento & 0,1088 & 0,0598 & $1.661 .531 \mathrm{ab}$ & $913.842 \mathrm{a}$ \\
\hline $9^{\circ}$ tratamento & $-0,0092$ & 0 & $0 \mathrm{~d}$ & $0 \mathrm{c}$ \\
\hline $10^{\circ}$ tratamento & 0,1011 & 0,0556 & $1.080 .759 \mathrm{bc}$ & $594.417 \mathrm{~b}$ \\
\hline Fo
\end{tabular}

Fonte: Autor, 2020

Médias seguidas pela mesma letra, na coluna, não diferem pelo teste de Tukey a 5\%.

1.Biogás gerado nos reatores

2.Metano gerado nos reatores

3.Estimativa de geração de biogás anual considerando a média anual de geração dos resíduos

4. Estimativa de geração de metano anual considerando a média anual de geração dos resíduos

Na Tabela 3 verifica-se a quantidade de biogás gerado na última avaliação realizada $\left(12^{\mathrm{a}}\right.$ semana) e a sua provável geração de gás metano presente no biogás. Considerando que o lodo biológico é o resíduo gerado em maior quantidade pela indústria, utilizou-se como referência no cálculo final, o valor médio anual deste rejeito gerado no período avaliado (1.069 ton.ano ${ }^{-1}$ ).

Observando o potencial de geração do biogás com os resíduos gerados na empresa, tendo como base o uso do lodo biológico, o $2^{\circ}$ tratamento com uma composição de $80 \%$ de lodo biológico, $10 \%$ de dregs e $10 \%$ de munha de carvão apresentou melhor desempenho com valor estimado de 1,8 milhão de $\mathrm{m}^{3}$ de biogás por ano, seguido pelo $6^{\circ}$ tratamento com $50 \%$ de lodo de 
esgoto, $40 \%$ de dregs e $10 \%$ de munha de carvão com, aproximadamente, 1,7 milhão de $\mathrm{m}^{3}$ de biogás estimado produzido por ano. Neste tratamento, apesar do desempenho da produção do biogás nos recipientes não ter apresentado alta produtividade $\left(0,0793 \mathrm{~m}^{3}\right)$, a relação da produção total do biogás aumenta significativamente quando a proporção do biogás é calculada com a utilização de todo lodo biológico. Os valores de produção de biogás anual deste tratamento ficaram próximos aos valores obtidos no $8^{\circ}$ tratamento que consistia na mistura de $70 \%$ de lodo biológico e $30 \%$ de dregs. O $10^{\circ}$ tratamento, que incluía apenas o lodo biológico, apresentou valores intermediários de produtividade de biogás, assim como na estimativa da produção total utilizando todo este rejeito gerado anualmente com 1,08 milhão de $\mathrm{m}^{3}$.

Os melhores rendimentos de produtividade e produção total das misturas dos diferentes rejeitos são importantes porque destina quase todo o material residual gerado pela empresa para a produção do biogás, devendo-se avaliar com mais critério a mistura da munha de carvão que, apesar de ser o resíduo gerado em menor quantidade, valores de munha na mistura acima de $15 \%$ inibe todo o processo de geração de biogás.

Em relação a produção do gás metano, utilizou-se uma proporção única de $55 \%$ do volume do biogás total segundo as referências. Estas variações estão associadas a diversos fatores. Bley et al (2009) descrevem que o biogás gerado a partir dos resíduos de animais gera biogás com teores de gás metano entre $40 \%$ e $70 \%$. Lobato (2011) descreve que o tratamento anaeróbico do lodo de esgoto, dependendo das condições ambientais, pode gerar entre $40 \%$ e $90 \%$ de gás metano presente no biogás gerado. Segundo Souza (2010), apesar do grande potencial de geração do metano oriundo do tratamento do lodo biológico, aproximadamente, $30 \%$ do gás gerado nos reatores permanecem solubilizados no efluente, demonstrando perdas no potencial energético. Considerando estes fatores, optou-se por estimar a concentração gasosa do metano no biogás em 55\%.

De acordo com Mello e Grassi (2014), uma boa alternativa já adotada amplamente em diversos países é a utilização do metano do biogás como fonte para a geração de energia elétrica. Para Figueiredo (2007) esse método seria uma boa alternativa, levando em conta o poder calorífico do metano de $35,736 \mathrm{KJ} / \mathrm{Nm}^{3}$. Dessa forma, quanto melhor a taxa de metano no biogás produzido, mais energia elétrica poderá ser produzida.

Segundo Andrade (2018), uma residência situada na região sudeste do Brasil consome em média 169,8KWh por mês. Para Barreira (2011), $1 \mathrm{~m}^{3}$ de biogás representa a geração de 1,43KW de energia elétrica. Com a máxima produção de biogás atingida pelo segundo tratamento, totalizando $1.803 .937 \mathrm{~m}^{3}$ ao ano de biogás seria possível suprir energeticamente 1.260 residências.

Considerando a possível geração de energia elétrica, por meio de biogás produzido na Cenibra, transformando em valores financeiros, em março de 2021, a Cemig cobrou de tarifa energética o valor de $\mathrm{R} \$ 0,9397 / \mathrm{KW}$. Aplicando à provável produção, o repasse de energia resultaria em $\mathrm{R} \$ 1.695 .159,60$ ano.

\section{CONSIDERAÇÕES FINAIS}

Após a análise dos dados, foi possível identificar o comportamento da produção de biogás e metano em relação aos materiais utilizados. O tratamento com maior quantidade de lodo biológico (100\%) ficou com a segunda maior produção total de biogás e o melhor desempenho no tratamento com a utilização da mistura de $80 \%$ de lodo biológico, $10 \%$ de dregs e $10 \%$ de munha de carvão. Nos tratamentos, onde a concentração de munha de carvão na mistura dos materiais foi igual ou superior a 20\%, não foi registrada a produção de biogás ao longo das 12 semanas avaliadas. Dessa forma, é possível concluir que a combinação dos materiais orgânicos inseridos no sistema é fundamental para a atividade microbiológica visando a produção de biogás no interior dos reatores.

O tratamento utilizado com a mistura da $50 \%$ de lodo biológico, $40 \%$ de dregs e $10 \%$ de munha de carvão apresentou desempenho de produção de biogás intermediário em relação aos 
demais tratamentos, mas considerando a disponibilidade média anual dos materiais na empresa, apresentou a segunda melhor estimativa de potencial de desempenho na produção de gás metano.

Verificou-se que o lodo da estação de tratamento da empresa é o material primordial do processo, mesmo não apresentando o valor mais elevado de produção de biogás quando utilizado de forma independente, sendo necessária a sua presença predominante na composição das misturas com dregs e munha de carvão utilizadas no processo de biodigestão.

\section{REFERÊNCIAS}

Almeida, H. C.; Silveira, C. B.; Ernani, P. R.; Campos, M. L. \& Almeida, D. (2007). Composição química de um resíduo alcalino da indústria de papel e celulose (Dregs). Química Nova, 30(7),1669-1672.

Andrade, J. R. (2018). Estudo sobre o potencial energético do resíduo sólido da Microrregião de Teófilo Otoni a partir da produção de metano. Dissertação (Mestrado). Universidade Federal dos Vales do Jequitinhonha e Mucuri. Programa de Pós-Graduação em Tecnologia, Ambiente e Sociedade.

Arroja, L. \& Louro, M. I. (2005). Gestão integrada de resíduos em fábricas de pasta para papel em Portugal. Capela Departamento de Ambiente e Ordenamento, Universidade de Aveiro, 3810-193 Aveiro, Portugal.

Barreira, P. (2011). Biodigestores: energia, fertilidade e saneamento para a zona rural. Ícone.

Barreto, V. C. de M.(2008). Resíduos de indústria de celulose e papel na fertilidade do solo e no desenvolvimento de eucalipto. 64p. Tese (Doutorado). Universidade Estadual Paulista, Faculdade de Ciências Agrárias e Veterinárias.

Bley JR, C.; Libânio, J. C.; Galinkim, M. \& Oliveira, M. M. (2009). Agroenergia da biomassa residual: perspectivas, energéticas, socioeconômicas e ambientais, (2 ${ }^{\mathrm{a}}$ Edição), Revista, Foz do Iguaçu/ Brasília, $138 \mathrm{p}$.

Bueno, F. T. (2018). O processo de industrialização da agricultura: um estudo da cana de açúcar no município de Uberaba-MG. Brasília, 114 p.

Budziak, C. R.; Maia, C. M. B. F. \& Mangrich, A. S. (2004). Transformações químicas da matéria orgânica durante a compostagem de resíduos da indústria madeireira. Química Nova, 27(3), 399-403.

Carvalho, A. G. M. (2002). A compostagem como processo catalisador para a reutilização dos resíduos de fábrica de celulose e papel. O Papel, 64(5),71-75.

Cenibra-Celulose Nipo-Brasileira S/A. (2018). Relatório de sustentabilidade. Recuperado em: nov. 2019 de: http://www.cenibra.com.br/cenibra/Relatorio\%20Web/www/ fscommand/PORTUGUES.pdf.

Cheunbarn, T. \& Pagilla, K. R. (2000). Anaerobic thermophilic/ mesophilic dual-stage sludge treatment. Environmental Engineering, 126,796-801.

Christian, J. H. B. \& Waltho, J. A. (1964). The composition of Staphylococcus aureus in relation to the water activity of the growth medium. Journal of Genetic Microbiology. 35,205-213.

Deivanai. K. \& Kasturi BAI, R. (1995). Batch biomethanation of banana trash and coir pith. Bioresource Technology, 52, 93-94.

Figueiredo, N. J. V. (2007). Utilização do Biogás de Aterro Sanitário para Geração de Energia Elétrica e Iluminação a Gás - estudo de caso. Universidade Presbiteriana Mackenzie, São Paulo, 90p. 
Foresti, E. (1998). Processos e operações em tratamento de resíduos SHS- 705. Pós-Graduação em Hidráulica e Saneamento na Escola de Engenharia de São Carlos. São Carlos.

Galbiatti, J. A.; Caramelo, A. D.; Silva, F. G.; Gerardi, E. A. B. \& Chiconato, D. A. (2010). Estudo quantitativo do biogás produzido por substratos em biodigestores tipo batelada. Revista Brasileira de Engenharia Sanitária e Ambiental ,14(4)1-12.

Gianfreda, L. \& Bolla G. J. M. (1996). Influence of natural and anthropogenic factors on enzyme activity in soil. In.: Stotsky, G.; Bollag, J.M. (E d.). Soil biochemistry. New York: Mareei Dekker, 9,123-193.

Gomes, X.; Cuetos, M. J.; Cara, J.; Moran, A. \& Garcia, A. I. (2006). Anaerobic co-digestion of primary sludege and the fruit and vegetable fraction of the municipal solid wastes: conditions for mixing and evaluation of the organic loading rate. Renewable Energy, 31, 2017-2024.

Ibá-Indústria Brasileira de Árvores. (2017). Relatório IBÁ 2017. Recuperado em: nov. 2019, de: https://www.iba.org/historico-de-desempenho.

Ju, F.; Wang, Y.; Lau, F. T. K.; Fung, W. C.; Huang, D.; Xia, Y. E. \& Zhang, T. (2016). Anaerobic digestion of chemically enhanced primary treatment (CEPT) sludge and the microbial community structure. Applied Microbiology and Biotechnology, 100, 8975-8982.

Kim, J.O. \& Chung, J. (2015). Inhibitory effects of inorganic and organic coagulants on acidogenic fermentation. KSCE Journal of Civil Engineering, 19(3), 572-577.

Konzen, E. A. (1983). Manejo e utilização de dejetos de suínos. Concórdia: Embrapa CNPSA, 32p.

Lima, L. (2020). Tratamento de efluente industrial de papel e celulose. Revista Foxwater, Campinas, São Paulo. 2020. Recuperado em: jan. 2021, de: https://www.foxwater.com.br/212/tratamento-de-efluenteindustrial-de-papel-e-celulose.

Lobato, L. C. S. (2011). Aproveitamento energético de biogás gerado em reatores UASB tratando esgoto doméstico. Tese (Doutorado). Saneamento, Meio Ambiente e Recursos Hídricos - Universidade Federal de Minas Gerais.

Lustosa, G. N. \& Medeiros, I. H. B. (2014). Proposta de um biodigestor anaeróbio modificado para produção de biogás e biofertilizante a partir de resíduos sólidos orgânicos. Departamento de Engenharia Civil e Ambiental, Universidade de Brasília, Brasília, DF, 72p.

Mello, A. R. \& Grassi, R. (2014). Avaliação do potencial de geração de energia elétrica a partir do biogás gerado no aterro sanitário do município de Francisco Beltrão - PR. Engenharia Ambiental - UTFPR, Câmpus Francisco Beltrão. 81p.

Mendonça, A. R. (2017). Crescimento de cenoura em solo com diferentes combinações de doses e granulometrias de carvão vegetal. 134p. Dissertação (mestrado) - Universidade Estadual Paulista, Faculdade de Ciências Agrárias e Veterinárias.

Moura, J. P. de. (2012). Estudo de casos das rotas tecnológicas para produção de biogás e da influência da composição química de dejetos de matrizes suínas na qualidade do biogás gerada por biodigestor. 122p.Tese (Doutorado), Engenharia Mecânica, Universidade Federal de Pernambuco.

Norkrans, B. (1966). Studies on marine-occuring yeast: growth related to $\mathrm{pH}, \mathrm{NaCl}$ concentration and temperature. Archeological Mikrobiology, 54, 374-392.

Obbard, J.P. \& Jones, K.C. (1993). The use of the cottonstrip assay to assess cellulose decomposition in heavy $\mathrm{m}$ etal-co $\mathrm{n}$ tam in ated sew age sludgeam ended soils. Environmental Pollution, 81,173-178. 
Ostrem, K. \& Themelis, N.J. (2004). Greening waste: anaerobic digestion for treating the organic fraction of municipal solid wastes. Columbia University, New York.

Paiva, S. N. (2007). Compósito cimento-lodo de ETE de indústria de papel para aplicação na construção civil. 111p. Dissertação (Mestrado), Recursos Florestais), Escola Superior de Agricultura - Universidade de São Paulo.

Pinheiro, R. M. (2008). Reciclagem do lodo primário da estação de tratamento de efluentes de indústria de papel em cerâmica argilosa. 102p. Dissertação (Mestrado), Centro de Ciência e Tecnologia, Universidade Estadual do Norte Fluminense Darcy Ribeiro, Campos dos Goytacazes, 102p.

Reichert, G. A. (2005). Aplicação da Digestão Anaeróbia de Resíduos Sólidos Urbanos: Uma Revisão. In: Congresso Brasileiro de Engenharia Sanitária e Ambiental, 23. Anais... ABES - Associação Brasileira de Engenharia Sanitária e Ambiental. Campo Grande - MS.

Rodrigues, A. M. \& Sant'Anna, E. S. (2001). Efeitos do cloreto de sódio na produção de proteínas (Saccharomyces cerevisiae) em fermentação semi-sólida. Ciência e Tecnologia de Alimentos., 21(1), 57-62.

Rodrigues, L. R; Francisco, M. A. C. O; Sagrillo, V. P. D; Louzada, D. M \& Entringer, J. M. S. (2016). Caracterização de resíduos sólidos da indústria de celulose tipo kraft visando sua aplicação no desenvolvimento de materiais cerâmicos. CBECiMat - Congresso Brasileiro de Engenharia e Ciência dos Materiais, 22, Brasil.

Rodrigues, C. M. (2004). Efeito da aplicação do resíduo da indústria de papel e celulose, nos atributos físicos, químicos e biológicos do solo, na nutrição e biomassa do Pinus taeda L. 121p. Dissertação (Mestrado), Agronomia, Universidade Federal do Paraná.

Santos, L. A.; Santos, A. F. M. S.; Valença, R. B.; Jucá, J. F. T. \& Oliveira, C. R. M. (2018). Produção de biogás a partir do bagaço de laranja. Revista Geama. 4(3), 22-27.

Silva, C. C.(2016). Aplicabilidade da gestão ambiental no Ambiente empresarial: análise na empresa Cerâmica Tarumã Ltda - ME de Itaituba/PA. Bacharelado em Administração da Faculdade de Itaituba FAI, Pará.

Silva, C. O.; Konrad, O.; Callado, N. H.; Marder, M. \& Araújo, L. G. S. (2020). Resíduos sólidos orgânicos domésticos como substrato potencial para produção de biogás. Revista Ibero Americana de Ciências Ambientais, 11(2), 204-212.

Silva, T. C.; Braz, R. L.; Araújo, E. C. G.; Silva, G. A. \& Padua, M. L. A. P. G.(2020). Produção de biogás utilizando biomassa de poda e lodo de esgoto no município de Recife (PE). Revista em Agronegócio e Meio ambiente. 44(1), 1-13.

Silva, C. M. M. de S. \& Vieira, R. F. (2008). Impacto de xenobióticos e metais pesados na microbiota do solo. Embrapa Meio Ambiente. Jaguariúna, SP.

Souza, C. L. (2010). Estudo das rotas de formação, transporte e consumo dos gases metano e sulfeto de hidrogênio resultantes do tratamento de esgoto doméstico em reatores UASB. 127p. Tese (Doutorado), Escola de engenharia da UFMG.

Souza, A.; Almeida, M. S. F.; Capello, L.; Santiago, T. T. A. Barreda, A. R. \& Oliveira, E. M. (2009). Produção de biogás como forma de reaproveitamento de resíduos da indústria cervejeira. Anais do Salão Internacional de Ensino, Pesquisa e Extensão da Unipampa, 11,11(21), 1-3.

Suzuki, A.B.P.; Feiden, A.; Fernandes, D.M.; Martins, G.I. \& Faria, R.A.P. (2012). Utilização de manipueira juntamente com sólidos da cama de aviário em biodigestores para geração de biogás. Ambiência, $8(3), 809-820$. 
Tajima, K.; Yoshizumi, H. \& Terashima, Y. (1966). Salt and sugar tolerances of yeast on alcoholic fermentation. I. The inhibition of fermentation by the highly concentrated salts in molasses. Journal of Fermentation Technology. 44, 77-84.

Toresan, L. (2012). Desempenho do setor florestal. In: Vieira, Luiz Marcelino (Coord.). Síntese anual da agricultura de Santa Catarina 2011-2012. Empresa de Pesquisa Agropecuária e Extensão Rural de Santa Catarina. Centro Socioeconômico e Planejamento Agrícola - Epagri/Cepa. Florianópolis, p.133 - 153.

Umemoto, S.; Irie, Y. \& Imai, T. (1967). The effect of electrolytes concentration on alcoholic fermentation of molasses. I. Glycerol accumulation in the medium caused by high concentrations of electrolytes. Journal of Fermentation Technology, 45,117-124.

Vieira, G. C. (2017). Inibição e toxicidade no processo de digestão anaeróbia dos lodos gerados na ETE Brasília Sul: estudo em escala laboratorial. Dissertação (Mestrado), Tecnologia Ambiental e Recursos Hídricos- Universidade de Brasília, Brasília, 78p.

Zhang, C.; Xiao, G.; Peng, L.; Su, H. \& Tan, T. (2013). The anaerobic co-digestion of food waste and cattle manure. Bioresource Technology, 129, 170-176.

\section{Como citar:}

Sylvio, A. Vieira, \& Ferreira, R. S. (2021). Avaliação da Produção de Biogás a Partir de Resíduos de uma Indústria de Celulose. Revista De Gestão Social E Ambiental, 15, e02720. https://doi.org/10.24857/rgsa.v15i1.2720 